\title{
A duplex real-time PCR assay for the detection and differentiation of Leishmania infantum and Leishmania tarentolae in vectors and potential reservoir hosts
}

\author{
Maria Stefania Latrofa ${ }^{1}$, Jairo Mendoza-Roldan ${ }^{1}$, Ranju Manoj ${ }^{1,1}$, Filipe Dantas-Torres ${ }^{2}$, \\ and Domenico Otranto ${ }^{1}$ \\ ${ }^{1}$ University of Bari \\ ${ }^{2}$ Fundacao Oswaldo Cruz
}

August 5, 2020

\begin{abstract}
Leishmanioses are vector-borne diseases caused by Leishmania spp., which are transmitted by phlebotomine sand flies (Diptera, Psychodidae). The recent reports in humans of Leishmania tarentolae, which is primarily found in cold-blooded animals, and Leishmania infantum in Sergentomyia minuta spurred us to develop an internal transcribed spacer 1-based duplex quantitative real-time PCR (dqPCR) assay for the detection and differentiation between these Leishmania spp. The specificity of dqPCR was assessed by processing DNA samples from Phlebotomus spp. $(\mathrm{n}=188)$ and Se. minuta $(\mathrm{n}=171)$ and from tissues (i.e., heart, liver, muscle, lungs, spleen, kidney, eggs) of Podarcis siculus $(n=4)$ and Tarentola mauritanica $(n=3)$. In the absence of naturally infected and/or co-infected lizards, DNA from cultured L. infantum and L. tarentolae were spiked into tissues of lizards and used as controls. The analytical sensitivity of the dqPCR, assessed using 10-fold serial dilutions of DNA from both Leishmania spp. and spiked DNA samples from lizards was $2.3 \times 10-7 \mathrm{ng} / 2 \mu \mathrm{l}$ for L. infantum and $2.1 \times 10-7 \mathrm{ng} / 2 \mu \mathrm{l}$ for L. tarentolae. With the spiked DNA samples, the dqPCR detected up to $2.6 \times 10-6 \mathrm{ng} / 2 \mu \mathrm{l}$ of L. infantum and up to $2.1 \times 10-7$ $\mathrm{ng} / 2 \mu \mathrm{l}$ of L. tarentolae. Of 359 phlebotomine sand flies tested, five (3.6\%) and two (1.4\%) Ph. perniciosus scored positive for L. infantum and L. tarentolae, respectively. Similarly, of 171 Se. minuta, $56(32.7 \%)$ and six (3.5\%) scored positive for L. tarentolae and L. infantum, respectively. Co-infection with both Leishmania spp. was detected in two Se. minuta (1.2\%). Out of seven reptiles tested, four P. siculus were positive for L. tarentolae. The newly dqPCR herein described may represent an improvement in the diagnosis of L. infantum and L. tarentolae and may assist in identifying the role of lizards as reservoirs and Se. minuta as vector, for these Leishmania spp.
\end{abstract}

A duplex real-time PCR assay for the detection and differentiation of Leishmania infantum and Leishmania tarentolae in vectors and potential reservoir hosts

Running Title : dqPCR for the detection and differentiation of $L$. infantum and L. tarentolae

Maria Stefania Latrofa ${ }^{a}$, Jairo Alfonso Mendoza-Roldan ${ }^{a}$, Ranju Ravindran Santhakumari Manoj $^{\mathrm{a}}$, Filipe Dantas-Torres ${ }^{\mathrm{b}}$, Domenico Otranto ${ }^{\mathrm{a}, \mathrm{c}}$

${ }^{a}$ Department of Veterinary Medicine, University of Bari, Valenzano, Italy

${ }^{\mathrm{b}}$ Aggeu Magalhães Institute, Oswaldo Cruz Foundation, Recife, Brazil

${ }^{\mathrm{c}}$ Faculty of Veterinary Sciences, Bu-Ali Sina University, Hamedan, Iran

${ }^{*}$ Corresponding author:

Domenico Otranto 
Department of Veterinary Medicine, University of Bari, Valenzano, 70010 Bari, Italy

Phone: +390805443839

E-mail address: domenico.otranto@uniba.it (D. Otranto)

\section{Summary}

Leishmanioses are vector-borne diseases caused by Leishmaniaspp., which are transmitted by phlebotomine sand flies (Diptera, Psychodidae). The recent reports in humans of Leishmania tarentolae, which is primarily found in cold-blooded animals, andLeishmania infantum in Sergentomyia minuta spurred us to develop an internal transcribed spacer 1-based duplex quantitative real-time PCR (dqPCR) assay for the detection and differentiation between these Leishmania spp. The specificity of dqPCR was assessed by processing DNA samples from Phlebotomus spp. $(\mathrm{n}=188)$ and Se. minuta $(\mathrm{n}=171)$ and from tissues (i.e., heart, liver, muscle, lungs, spleen, kidney, eggs) of Podarcis siculus $(\mathrm{n}=4)$ and Tarentola mauritanica $(\mathrm{n}=3)$. In the absence of naturally infected and/or co-infected lizards, DNA from cultured L. infantum and L. tarentolae were spiked into tissues of lizards and used as controls. The analytical sensitivity of the dqPCR, assessed using 10-fold serial dilutions of DNA from both Leishmania spp. and spiked DNA samples from lizards was 2.3 $\mathrm{x} 10^{-7} \mathrm{ng} / 2 \mu \mathrm{l}$ for $L$. infantum and $2.1 \times 10^{-7} \mathrm{ng} / 2 \mu \mathrm{l}$ for $L$. tarentolae. With the spiked DNA samples, the dqPCR detected up to $2.6 \times 10^{-6} \mathrm{ng} / 2 \mu \mathrm{l}$ of $L$. infantum and up to $2.1 \times 10^{-7} \mathrm{ng} / 2 \mu \mathrm{l}$ of L. tarentolae . Of 359 phlebotomine sand flies tested, five $(3.6 \%)$ and two (1.4\%) Ph. perniciosus scored positive for L. infantumand L. tarentolae, respectively. Similarly, of 171 Se. minuta , 56 (32.7\%) and six (3.5\%) scored positive for $L$. tarentolae and $L$. infantum, respectively. Co-infection with bothLeishmania spp. was detected in two Se. minuta (1.2\%). Out of seven reptiles tested, four P. siculus were positive for $L$. tarentolae . The newly dqPCR herein described may represent an improvement in the diagnosis of $L$. infantum and $L$. tarentolae and may assist in identifying the role of lizards as reservoirs and Se. minuta as vector, for these Leishmaniaspp.

Key words: duplex real-time PCR, ITS1, Leishmania infantum, Leishmania tarentolae, Lizards, Sergentomyia minuta

\section{Introduction}

Leishmanioses are vector-borne diseases that cause clinical conditions of varying degrees to different mammal species, including humans. The diseases are caused by Leishmania spp. (Kinetoplastida, Trypanosomatidae), which are transmitted by bites of phlebotomine sand flies of the genera Phlebotomus in the Old World (Maroli et al., 2013). Among the circa 100 sand flies species indicated as proven vectors of Leishmania spp. (Maroli et al., 2013), some are highly specific for certain Leishmania spp. (e.g., Phlebotomus sergenti and Phlebotomus papatasi for Leishmania tropicaand Leishmania major , respectively) (Kamhawi, 2006), whereas others support the development of more than one Leishmania spp. (i.e., Phlebotomus arabicus is susceptible to the development of both L. major and Leishmania infantum ) being considered permissive vectors (Jacobson et al., 2003; Myskova et al., 2007). However, DNA of Leishmania spp. may be retrieved in non-competent vectors such as in the case of L. tropica and L. major inPhlebotomus perniciosus and L. infantum inPhlebotomus mascittii (Vaselek et al., 2017; Gherbi et al., 2020). Meanwhile, phlebotomine sand flies of the genusSergentomyia are known to feed primarily on cold-blooded animals (Lewis, 1987) and are associated to the transmission ofLeishmania (Sauroleishmania) spp. in lizards (Killick-Kendrick et al., 1986; Lewis, 1987; Noyes et al., 1997; Tuon et al., 2008). These reptiles have also been found molecularly positive for some Leishmania spp. pathogenic to humans (Pombi et al., 2020). For example, DNA of L. major, L. tropica and Leishmania martiniquensis were found in different species of Sergentomyia(e.g., Sergentomyia barraudi, Sergentomyia darling ,Sergentomyia garhami, Sergentomyia clydei, Sergentomyia gemmea, and Sergentomyia iyengari ) (Mutinga et al., 1994; Berdjane-Brouk et al., 2012; Kanjanopas et al., 2013; Nzelu et al., 2014; Ayari et al., 2016; Siripattanapipong et al., 2018). Similarly, the DNA of $L$. infantum has been detected in severalSergentomyia spp., such as Sergentomyia dubia ,Sergentomyia magna and Sergentomyia schewtzi in Africa (Senghor et al., 2016), and Sergentomyia minuta from areas endemic for canine leishmaniosis in Europe (Tarallo et al., 2010; Campino et al., 2013; Bravo-Barriga et al., 2016; 
Maia et al., 2015; Latrofa et al., 2018; Gonzales et al., 2020; Pombi et al., 2020).

Sergentomyia spp. female is known to feed mostly on cold-blooded animals, such as lizards, which are, with geckos, the primary hosts ofLeishmania tarentolae (Telford 1995; Sloboda et al., 2007; Halla et al., 2014). This Leishmania species is considered non-pathogenic for mammals, although some strains (e.g., LEM-125) were associated to transient infectious in rodents and humans (Adler, 1962; Breton, 2005; Taylor et al., 2010; Novo et al., 2015). On the contrary, the DNA and/or amastigote forms of pathogenic Leishmania spp. (i.e., L. tropica, Leishmania donovani and L. infantum ) have been detected in reptiles (Wilson and Southgate, 1979; Simpson and Holtz, 1988; Belova, 1971; Zhang et al., 2019; Chen et al., 2019) . Therefore, in addition to mammals and various other hosts such as black rat, hares, horse, cat, red fox and wild carnivores (Criado-Fornelio et al., 2000; Solano-Gallego et al., 2003; Sobrino et al., 2008; Millán et al., 2011; Gramiccia, 2011; Montoya et al., 2016), reptiles have been suggested as potential reservoirs for different Leishmania spp. (Zhang et al., 2016; Mendoza-Roldan et al., 2020).

The recent reports of $L$. tarentolae in human blood and of L. infantum in Se. minuta (Latrofa et al., 2018; Gonzales et al., 2020; Pombi et al., 2020) spurred us to develop a duplex quantitative real-time PCR (dqPCR), with species-specific probes targeting the internal transcribed spacer 1 (ITS1) region, for the detection and differentiation between $L$. infantum and $L$. tarentolae. This assay may provide a fundamental contribution for understand the potential ecological role of sand flies and reptiles in spreading these two parasites in endemic and non-endemic geographical areas where they live in sympatry with animals and humans.

\section{Materials and Methods}

\subsection{Samples}

To obtain sequences of Leishmania spp. for primes and probes designing, promastigotes of L. infantum (zymodeme MON-1; $1.6 \times 10^{7}$ promastigotes/ml) and L. tarentolae (strain RTAR/IT/81/ISS21-G.6c; 1.7 x $10^{7}$ promastigotes/ml) were extracted and their genomic DNA (gDNA) amplified by conventional PCR using primes (L5.8S/LITSR) targeting a fragment of the ITS1 (300-350 bp), as described elsewhere (El Tai et al., 2001). Genomic DNA ofL. major (MHOM/TM/1973/5ASKH), L. aethiopica(MHOM/ET/72/L100), L. donovani (MHOM/IN/00/DEVI) and L. tropica (MHOM/IL/2005/LRC-L1239) were also used for testing the specificity of the newly developed assay (see below).

2.2 Primers, probes, and dqPCR protocol

Generic primers (L.i.t. -ITS1-F 5'-GCAGTAAAAAAAAGGCCG-3'; L.i.t. $\quad$-ITS1-R 5'CGGCTCACATAACGTGTCGCG-3') and two specific hydrolysis TaqMan-MGB probes (L.t. -6-FAM-5'-CACGCCGCGTATACAAAAACAC-3'-non-fluorescent quencher-MGB; L.i.- $\quad$ VIC-5'TAACGCACCGCCTATACAAAAGCA-3'-non-fluorescent quencher-MGB (Applied Biosystems; Foster City, CA, USA) targeting $150 \mathrm{bp}$ of the ITS1 of L. infantum and L. tarentolae, were designed by alignment of the reference Leishmania spp. sequences using Primer Express 2.0 (Applied Biosystems, Foster City, CA). Sequences of L. major (accession number HG512924), L. tropica (accession number HG512927), L. turanica (accession number AJ272382) and Leishmania aethiopica (accession number HG512923) available from GenBank were included in the alignment. The primer and probe specificity were analysed in silico using the basic local alignment search tool (BLAST; http://blast.ncbi.nlm.nih.gov/Blast.cgi). dqPCR reactions were carried out in a final volume of $20 \mu \mathrm{l}$, consisting of $10 \mu \mathrm{l}$ of IQ Supermix (Bio-Rad Laboratories, Hercules CA, USA), $7 \mu \mathrm{l}$ of Di-Ethyl Pyro-Carbonate (DEPC) treated pyrogen-free DNase/RNase-free water (Invitrogen, Carlsbad, CA, USA), $2 \mu \mathrm{l}$ of template DNA and $950 \mathrm{nM}$ of each primer, as well as 200 and $300 \mathrm{nM}$ of FAM and VIC TaqMan-MGB probes, respectively. The thermal cycling conditions consisted of a hot start at $95^{\circ} \mathrm{C}$ for $3 \mathrm{~min}$, and 40 cycles of denaturation $\left(95^{\circ} \mathrm{C}\right.$ for $\left.10 \mathrm{sec}\right)$ and annealing-extension $\left(55^{\circ} \mathrm{C}\right.$ for $\left.30 \mathrm{sec}\right)$. All assays were carried out in duplicate and a no-template control (NTC) was included in each run. The dqPCR was performed in a CFX96 ${ }^{\mathrm{TM}}$ Real-Time System (Bio-Rad Laboratories, Inc., Hercules CA, USA) and the increase in the fluorescent signals were registered during the extension step of the reaction and analysed by the CFX Manager ${ }^{\mathrm{TM}}$ software, version 3.1 (Bio-Rad). 


\subsection{Specificity and sensitivity of the dqPCR}

To investigate the analytical specificity of the assay, gDNA of both $L$. infantum and $L$. tarentolae, alone or in combination, as well as gDNA of L. major, L. aethiopica, L. donovani and L. tropica were tested. In addition, DNA fromPhlebotomus spp. (i.e., five Ph. neglectus, threePh. papatasi, $140 \mathrm{Ph}$. perniciosus, and $40 \mathrm{Ph}$. perfiliewi) and Se. minuta $(\mathrm{n}=171)$ previously collected in aL. infantum -endemic area ( Latrofa et al., 2018; Iatta et al., 2020) (Table 1) and DNA from various types of samples (i.e., heart, liver, muscle, lungs, spleen, kidney, and eggs), from four Italian wall lizards (Podarcis siculus ) and three Moorish wall geckos (Tarentola mauritanica) were tested. In addition, in the absence of naturally infected and/or co-infected lizard samples, DNA from L. infantum and L. tarentolae were spiked with the DNA from lizard samples and used as controls (Table 2).

The analytical sensitivity of the dqPCR assay was assessed using 10-fold serial dilutions of DNA from $L$. infantum (ranging from $2.7 \times 10^{-1}$ to $2.7 \times 10^{-8} \mathrm{ng} / 2 \mu \mathrm{l}$ of reaction), L. tarentolae (ranging from $2.1 \times 10^{-1}$ to $2.1 \times 10^{-8} \mathrm{ng} / 2 \mu \mathrm{l}$ of reaction) and from the spiked DNAs of both Leishmania species (ranged from 2.4 $\times 10^{-1}$ to $2.4 \times 10^{-8} \mathrm{ng} / 2 \mu \mathrm{l}$ of reaction) and expressed also by threshold cycle values (Cq) and parasite load amount (promastigotes $/ 2 \mu \mathrm{l}$ of reaction). gDNA was extracted from Leishmania spp. cultures and from lizard tissues using the commercial kit DNeasy Blood \& Tissue (Qiagen, GmbH, Hilden, Germany), following the manufacturer's instructions. The amount of purified DNA from each Leishmaniastrain $(L$. infantum = $2.6 \times 10^{-1} \mathrm{ng} / \mu \mathrm{l} ;$ L. tarentolae $=2.1 \times 10^{-1} \mathrm{ng} / \mu \mathrm{l}$ ) was determined using Qubit (Applied Biosystems, Foster City, CA, USA).

\section{Results}

Fluorescent signals were recorded for DNA of $L$. infantum and L. tarentolae, and for the spiked DNA from both Leishmaniaspp. (Figure 1 A, B, C). Though BLASTn analyses did not found sequences identity with other Leishmania spp., fluorescence signals were obtained for $L$. donovani $(\mathrm{Cq}=16.5)$, L. tropica $(\mathrm{Cq}=16.2)$ and L. major $(\mathrm{Cq}=17.7)$ tested with the VIC-L. infantumprobe, whilst no fluorescence signals were obtained with otherLeishmania spp., or NTC. The performance of the assay was confirmed by the efficiency values (ranging from 106.5 to 115\%) of the standard curves obtained with each Leishmania spp. and for spiked DNAs, with $\mathrm{R}^{2}$ ranging from 0.978 to 1.000 and the slope ranging from -3.009 to -3.178 (Figure $1 \mathrm{~A}, \mathrm{~B}, \mathrm{C}$ ). The analytical sensitivity of the dqPCR was $2.3 \times 10^{-7} \mathrm{ng} / 2 \mu \mathrm{l}$ for $L$. infantum (i.e., $3.3 \times 10^{-3}$ promastigotes $/ 2$ $\mu \mathrm{l}, \mathrm{Cq}$ of 37.4 ) and $2.1 \times 10^{-7} \mathrm{ng} / 2 \mu \mathrm{l}$ for L. tarentolae (i.e., $3.3 \times 10^{-3}$ promastigotes $/ 2 \mu \mathrm{l}$, Cq of 36.3). With the spiked DNA, the assay detected up to $2.6 \times 10^{-6} \mathrm{ng} / 2 \mu \mathrm{l}$ of $L$. infantum (i.e., $3.3 \times 10^{-2}$ promastigotes $/ 2$ $\mu \mathrm{l}, \mathrm{Cq}$ of 38.0 ) and up to $2.1 \times 10^{-7} \mathrm{ng} / 2 \mu \mathrm{l}$ for L. tarentolae (i.e., $3.3 \times 10^{-3}$ promastigotes $/ 2 \mu \mathrm{l}, \mathrm{Cq}$ up to $38.6)$.

Out of 359 phlebotomine sand flies tested, 63 (17.5\%) scored positive for Leishmania spp. (Table 1) with five (3.6\%) and two (1.4\%) Ph. perniciosus specimens, positive for L. infantum and L. tarentolae, respectively (Table 1). Out of 171Se. minuta tested, $56(32.7 \%)$ scored positive for L. tarentolae and six (3.5\%) for $L$. infantum . Co-infection with both Leishmania spp. was detected in two samples of Se. minuta (1.2\%). No $P h$. papatasi, Ph. neglectus and Ph. perfiliewi scored positive for Leishmania spp. (Table 1). The mean DNA load detected in phlebotomine sand flies ranged from $2.2 \times 10^{-5}$ to $3.0 \mathrm{ng} / 2 \mu \mathrm{l}$ for L. infantum (mean Cq up to 35.3) and from $2.1 \times 10^{-6}$ to $4.1 \mathrm{ng} / 2 \mu \mathrm{l}$ for L. tarentolae (mean Cq up to 35.9) (Table 1).

Out of seven reptiles tested, four P. siculus were naturally infected by L. tarentolae. In particular, of the five types of lizard tissue analysed, one each of muscle, heart and spleen (Cq values ranging from 34.1 to 36.9 , corresponding to $2.3 \times 10^{-1}$ and $2.9 \times 10^{-2}$ promastigotes $/ 2 \mu \mathrm{l}$ ) and two each of kidney and egg samples (Cq value ranging from 20.3 to 37.2 , corresponding to $3.5 \times 10^{3}$ and $3.1 \times 10^{-2}$ promastigotes $/ 2 \mu l$ ) scored positive for L. tarentolae. All DNA samples from lizard spiked with DNA of L. infantum and/or $L$. tarentolae returned positive signals for one or both species (Table 2). Similar mean Cq values were detected for all tissues spiked with each Leishmania spp. (ranging from 19.0 to 21.4), with the exclusion of lung samples of T. mauritanica, where an increasing Cq values up to 25 were detected (Table 2). A slightly increased Cq values was obtained by testing spiked lizard samples with both Leishmania spp. (Table 2). 


\section{Discussion}

The dqPCR assay, developed for the simultaneous detection and differentiation of $L$. infantum and $L$. tarentolae, proved to be an efficient and sensitive tool for detecting both parasites, alone or in combination. In particular, the smallest amount of DNA detected $\left(2.1 \times 10^{-7} \mathrm{ng} / 2 \mu \mathrm{l}\right.$ for L. tarentolaeand $2.6 \times 10^{-6} \mathrm{ng} / 2$ $\mu$ for $L$. infantum $)$ corresponded to a low parasite load $\left(3.3 \times 10^{-3}\right.$ and $3.3 \times 10^{-3}$ promastigotes $/ 2 \mu l$ per reaction). However, a slight shift in the $\mathrm{Cq}$ values was observed for $L$. infantum and $L$. tarentole spiked with DNA samples from lizards. The results obtained may be explained by the copy number (i.e., 200) of the genetic target (ITS1) present in the genome of Leishmania spp. (Van der Auwera and Dujardin 2015; Schonian et al., 2011) and by the high genetic variability of this region, which was pivotal for delineating the two species. Indeed, differently from the minicircle kinetoplast DNA, which exhibits a high sensitivity in detecting low amounts of DNA (equivalent to 0.004 parasites) but low specificity (Kuhls et al., 2011; Galluzzi et al., 2018), the ITS1 has been successfully used to resolve taxonomical and phylogenetic relationships among closely related Leishmaniaspp. (Dávila and Momen, 2000; Parvizi and Amirkhani, 2008; Wang et al., 2010; Hajjaran et al., 2013).

The sensitivity of the dqPCR (100\%) was also confirmed by detection of DNA of both Leishmania spp. in all lizard spiked DNA samples, showing approximately the same Cq values (ranging from 19.0 to 22.1). Similarly, the good performance of the dqPCR was also determined by the values of the slope of standard curves, the efficiency and the coefficient of determination obtained with both Leishmania spp. and the lizard-spiked DNA.

The dqPCR assay detected low amounts of Leishmania spp. DNA (mean value of $2.2 \times 10^{-5}$ for L. infantum and $2.1 \times 10^{-6}$ for L. tarentolae ) in naturally infected phlebotomine sand flies as well as discriminated both species in co-infected Se. minuta. Though a low number of phlebotomine sand flies were tested, the finding of the same prevalence of infection for L. infantum in Ph. perniciosus (3.6\%) and in Se. minuta (3.5\%) and the co-infection for both Leishmania spp. provide additional circumstantial evidence on the involvement ofSe. minuta in the circulation of L. infantum in some endemic areas (Maia et al., 2015; Maia and Depaquit, 2016; Latrofa et al., 2018; Pombi et al., 2020). Indeed, the role of Se. minuta in spreading Leishmania spp. other than L. tarentolae has been suggested in different countries of the Mediterranean region such as Italy, Portugal, Tunisia and Turkey ( Campino et al., 2013; Jaouadi et al., 2015; Maia et al., 2015; Ayari et al., 2016; Özbel et al., 2016; Latrofa et al., 2018) and also in regions of Africa (Mutinga et al., 1994; Tateng et al., 2018; Nzelu et al., 2014) and Asia (Chusri, et al., 2014; Siripattanapipong et al., 2018). Therefore, given the opportunistic anthropophilic feeding behaviour of this phlebotomine sand fly, susceptible hosts could be infected by L. infantum through bites of Se. minuta females (Maia et al., 2015; Gonzales et al., 2020; Pombi et al., 2020). In this context, the pathogenic role of $L$. tarentolae detected in humans should not be ruled out. Indeed, some virulence factors, (i.e., GP63, CPB, LPG3 and amastin) present in the pathogenic L. infantum and L. major is also expressed in L. tarentolae (Azizi et al., 2009; Mizbani et al., 2011; Raymond et al., 2012; Novo et al., 2015) . The detection of the DNA of L. tarentole in P. siculus suggest that more than one lizard species could be infected by this pathogen, besides the previously reported T. mauritanica (Pozio et al., 1983). Finally, even if no lizard samples scored positive for L. infantum in the present investigation, the limited number of samples tested precludes any further inference on this.

In conclusion, the dqPCR herein described may represent an improvement in the discrimination of $L$. infantum and L. tarentolae in order to identify the role of lizards and Se. minuta as reservoirs and vector, respectively, for these Leishmania spp. Furthermore, this assay will allow large-scale testing of humans (and also dogs, for instance) in areas where Se. minuta occurs, enabling a more robust assessment on how frequent these hosts are exposed to L. tarentolae .

\section{Authorship}

Conceptualization, Maria Stefania Latrofa, Jairo Alfonso Mendoza-Roldan, Domenico Otranto; Methodology, Maria Stefania Latrofa, Ranju Ravindran Santhakumari Manoj; Formal Analysis, Maria Stefania Latrofa, Ranju Ravindran Santhakumari Manoj; Data Curation, Maria Stefania Latrofa, Ranju Ravindran Santha- 
kumari Manoj, Domenico Otranto; Writing - Original Draft Preparation, Maria Stefania Latrofa, Domenico Otranto; Writing - Review \& Editing, Maria Stefania Latrofa, Jairo Alfonso Mendoza-Roldan, Ranju Ravindran Santhakumari Manoj, Filipe Dantas-Torres, Domenico Otranto.

\section{Conflicts of Interest}

The authors declare no conflict of interest.

\section{Ethical Statement}

The authors confirm that the ethical policies of the journal, as noted on the journal's author guidelines page, have been adhered to the European Directive 2010/63/EU and the study was approved by the ethical committee of the Department of Veterinary Medicine of the University of Bari, Italy (Prot. Uniba 7/17) and of Ministry authorization (ISPRA Prot 73267; 31/12/2019).

\section{Data Availability Statement}

The data that support the findings of this study are available from the corresponding author.

\section{References}

Adler, S. (1962). The behaviour of a lizard Leishmania in hamsters and baby mice. Revista Do Instituto de Medicina Tropical de São Paulo, 4, 61-64.

Ayari, C., Ben Othman, S., Chemkhi, J., Tabbabi, A., Fisa, R., Ben Salah, A., \& BenAbderrazak, S. (2016). First detection ofLeishmania major DNA in Sergentomyia (Sintonius ) clydei (Sinton, 1928, Psychodidae: Phlebotominae), from an outbreak area of cutaneous leishmaniasis in Tunisia. Infection, Genetics and Evolution, 39, 241-248. https://doi.org/10.1016/j.meegid.2015.10.030

Azizi, H., Hassani, K., Taslimi, Y., Najafabadi, H. S., Papadopoulou, B., \& Rafati, S. (2009). Searching for virulence factors in the non-pathogenic parasite to humans Leishmania tarentolae . Parasitology, 136(7), 723-735. https://doi.org/10.1017/S0031182009005873

Azizi, K., Askari, M. B., Kalantari, M., \& Moemenbellah-Fard, M. D. (2016). Molecular detection of Leishmania parasites and host blood meal identification in wild sand flies from a new endemic rural region, south of Iran. Pathogens and Global Health, 110(7-8), 303-309. https://doi.org/10.1080/20477724.2016.1253530

Belova, E. M. (1971). Reptiles and their importance in the epidemiology of leishmaniasis. Bulletin of the World Health Organization, 44(4), 553-560.

Berdjane-Brouk, Z., Koné, A. K., Djimdé, A. A., Charrel, R. N., Ravel, C., Delaunay, P., del Giudice, Diarra, A.Z., Doumbo, S., Goita, S., Thera, M.A., Depaquit, J., Marty, P., Doumbo, O.K., \& Izri, A. (2012). First detection of Leishmania major DNA in Sergentomyia (Spelaeomyia) darlingi from cutaneous leishmaniasis foci in Mali. PLoS ONE, 7(1). https://doi.org/10.1371/journal.pone.0028266

Bravo-Barriga, D., Parreira, R., Maia, C., Blanco-Ciudad, J., Afonso, M. O., Frontera, E., Campino, L., Pérez-Martín, J.E., Serrano Aguilera, F.J., \& Reina, D. (2016). First molecular detection of Leishmania tarentolae -like DNA in Sergentomyia minuta in Spain. Parasitology Research, 115(3), 1339-1344. https://doi.org/10.1007/s00436-015-4887-z

Breton, M., Tremblay, M. J., Ouellette, M., \& Papadopoulou, B. (2005). Live nonpathogenic parasitic vector as a candidate vaccine against visceral leishmaniasis. Infection and Immunity, 73(10), 6372-6382. https://doi.org/10.1128/IAI.73.10.6372-6382.2005

Campino, L., Cortes, S., Dionísio, L., Neto, L., Afonso, M. O., \& Maia, C. (2013). The first detection of Leishmania major in naturally infected Sergentomyia minuta in Portugal. Memórias Do Instituto Oswaldo Cruz, 108(4), 516. https://doi.org/10.1590/0074-0276108042013020 
Chen, H., Li, J., Zhang, J., Guo, X., Liu, J., He, J., Song, Q., Zhang, J., Chen, M., Zheng, Z., Chen, D., \& Chen, J. (2019). Multi-locus characterization and phylogenetic inference of Leishmania spp. in snakes from Northwest China. PLOS ONE, 14(4), e0210681. https://doi.org/10.1371/journal.pone.0210681

Chusri, S., Thammapalo, S., Silpapojakul, K., \& Siriyasatien, P. (2014). Animal reservoirs and potential vectors of Leishmania siamensis in southern Thailand. Southeast Asian Journal of Tropical Medicine and Public Health, 45(1), 13-19.

El Tai, N. O., El Fari, M., Mauricio, I., Miles, M. A., Oskam, L., El Safi, S. H., Presber, W.H., \& Schönian, G. (2001). Leishmania donovani : Intraspecific polymorphisms of Sudanese isolates revealed by PCR-based analyses and DNA sequencing. Experimental Parasitology, 97(1), 35-44. https://doi.org/10.1006/expr.2001.4592

Galluzzi, L., Ceccarelli, M., Diotallevi, A., Menotta, M., \& Magnani, M. (2018). Real-time PCR applications for diagnosis of leishmaniasis. Parasites and Vectors, 11, 273. https://doi.org/10.1186/s13071-018-2859-8

Gherbi, R., Bounechada, M., Latrofa, M. S., Annoscia, G., Tarallo, V. D., Dantas-Torres, F., \& Otranto, D. (2020). Phlebotomine sand flies and Leishmania species in a focus of cutaneous leishmaniasis in Algeria. PLOS Neglected Tropical Diseases, 14(2), e0008024. https://doi.org/10.1371/journal.pntd.0008024

González, E., Molina, R., Aldea, I., Iriso, A., Tello, A., \& Jiménez, M. (2020). Leishmania sp. detection and blood-feeding behaviour of Sergentomyia minuta collected in the human leishmaniasis focus of Southwestern Madrid, Spain (2012-2017). Transboundary and Emerging Diseases, 67(3), 1393-1400. https://doi.org/10.1111/tbed.13464

Gramiccia, M. (2011). Recent advances in leishmaniosis in pet animals: epidemiology, diagnostics and antivectorial prophylaxis. Veterinary Parasitology, 181(1), 23-30. https://doi.org/10.1016/j.vetpar.2011.04.019

Hajjaran, H., Mohebali, M., Mamishi, S., Vasigheh, F., Oshaghi, M. A., Naddaf, S. R., Teimouri, A., Hossein Edrissian, G., \& Zarei, Z. (2013). Molecular identification and polymorphism determination of cutaneous and visceral leishmaniasis agents isolated from human and animal hosts in Iran. BioMed Research International, 2013. https://doi.org/10.1155/2013/789326

Iatta, R., Zatelli, A., Laricchiuta, P., Legrottaglie, M., Modry, D., Dantas-Torres, F., \& Otranto, D. (2020). Leishmania infantum in tigers and sand flies from a leishmaniasis-endemic erea, southern Italy. Emerging Infectious Diseases, 26(6), 1311-1314. https://doi.org/10.3201/EID2606.191668

Jacobson, R. L., Eisenberger, C. L., Svobodova, M., Baneth, G., Sztern, J., Carvalho, J., Nasereddin, A., El Fari, M., Shalom, U., Volf, P., Votypka, J., Dedet, J.P., Pratlong, F., Schonian, G., Schnur, L.F., Jaffe, C.L., \& Warburg, A. (2003). Outbreak of cutaneous leishmaniasis in northern Israel. Journal of Infectious Diseases, 188(7), 1065-1073. https://doi.org/10.1086/378204

Jaouadi, K., Ghawar, W., Salem, S., Gharbi, M., Bettaieb, J., Yazidi, R., Harrabi, M., Hamarsheh, O., \& Ben Salah, A. (2015). First report of naturally infected Sergentomyia minuta with Leishmania major in Tunisia. Parasites and Vectors, 8, 649. https://doi.org/10.1186/s13071-015-1269-4

Kamhawi, S. (2006). Phlebotomine sand flies and Leishmaniaparasites: friends or foes? Trends in Parasitology, 22, 439-445. https://doi.org/10.1016/j.pt.2006.06.012

Kanjanopas, K., Siripattanapipong, S., Ninsaeng, U., Hitakarun, A., Jitkaew, S., Kaewtaphaya, P., Tanariya, P., Mungthin, M., Charoenwong, C., \& Leelayoova, S. (2013). Sergentomyia(Neophlebotomus ) gemmea, a potential vector ofLeishmania siamensis in southern Thailand. BMC Infectious Diseases, 13, 333. https://doi.org/10.1186/1471-2334-13-333

Killick-Kendrick, R., Lainson, R., Rioux, J. A., \& Sarjanova, V. M. (1986). The taxonomy of Leishmanialike parasites of reptiles. In: Rioux J. A., (ed.). Leishmania taxonomie et phylogenese Applications ecoepidimiologique. Montpellier. 
Kuhls, K., Alam, M. Z., Cupolillo, E., Ferreira, G. E. M., Mauricio, I. L., Oddone, R., Feliciangeli, M.D., Wirth, T., Miles, M.A., \& Schonian, G. (2011). Comparative microsatellite typing of new worldLeishmania infantum reveals low heterogeneity among populations and its recent old world origin. PLoS Neglected Tropical Diseases, 5(6): e1155. https://doi.org/10.1371/journal.pntd.0001155

Latrofa, M. S., Iatta, R., Dantas-Torres, F., Annoscia, G., Gabrielli, S., Pombi, M., Gradoni, L., \& Otranto, D. (2018). Detection ofLeishmania infantum DNA in phlebotomine sand flies from an area where canine leishmaniosis is endemic in southern Italy. Veterinary Parasitology, 253, 39-42. https://doi.org/10.1016/j.vetpar.2018.02.006

Lewis, D. J. (1987). Phlebotomine sandflies (Diptera: Psychodidae) from the Oriental Region. Systematic Entomology, 12(2), 163-180. https://doi.org/10.1111/j.1365-3113.1987.tb00194.x

Davila, A. M. R., \& Momen, H. (2000). Internal-transcribed-spacer (ITS) sequences used to explore phylogenetic relationships withinLeishmania . Annals of Tropical Medicine and Parasitology, 94(6), 651-654. https://doi.org/10.1080/00034980050152085

Maia, C. (2016). Can Sergentomyia (Diptera, Psychodidae) play a role in the transmission of mammalinfecting Leishmania ? Parasite, 23, 55. https://dx.doi.org/10.1051\%2Fparasite\%2F2016062

Maia, C., Parreira, R., Cristovao, J. M., Freitas, F. B., Afonso, M. O., \& Campino, L. (2015). Molecular detection of Leishmania DNA and identification of blood meals in wild caught phlebotomine sand flies (Diptera: Psychodidae) from southern Portugal. Parasites and Vectors, 8, 173. https://doi.org/10.1186/s13071-0150787-4

Maroli, M., Feliciangeli, M. D., Bichaud, L., Charrel, R. N., \& Gradoni, L. (2013). Phlebotomine sandflies and the spreading of leishmaniases and other diseases of public health concern. Medical and Veterinary Entomology, 27, 123-147. https://doi.org/10.1111/j.1365-2915.2012.01034.x

Mendoza-Roldan, J., Modry, D., \& Otranto, D. (2020). Zoonotic parasites of reptiles: a crawling threat. Trends in Parasitology, 36, 677-687. https://doi.org/10.1016/j.pt.2020.04.014

Millan, J., Zanet, S., Gomis, M., Trisciuoglio, A., Negre, N., \& Ferroglio, E. (2011). An investigation into alternative reservoirs of canine leishmaniasis on the endemic island of Mallorca (Spain). Transboundary and Emerging Diseases, 58(4), 352-357. https://doi.org/10.1111/j.1865-1682.2011.01212.x

Mizbani, A., Taslimi, Y., Zahedifard, F., Taheri, T., \& Rafati, S. (2011). Effect of A2 gene on infectivity of the nonpathogenic parasiteLeishmania tarentolae. Parasitology Research, 109(3), 793-799. https://doi.org/10.1007/s00436-011-2325-4

Montoya, A., De Quadros, L. P., Mateo, M., Hernandez, L., Galvez, R., Alcantara, G., Checa, R., Jimenez, M.A., Chicharro, C., Cruz, I., \& Miro, G. (2016). Leishmania infantum infection in Bennett's wallabies (Macropus rufogriseus rufogriseus ) in a Spanish wildlife park. Journal of Zoo and Wildlife Medicine, 47(2), 586-593. https://doi.org/10.1638/2014-0216.1

Mutinga, M., Massamba, N. N., Basimike, M., Kamau, C.C., Amimo, F.A., Onyido, A.E., Omogo, D.M., Kyai, F.M., \& Wachira, D.W. (1994). Cutaneous leishmaniasis in Kenya: Sergentomyia garnhami (Diptera Psychodidae), a possible vector of Leishmania major in Kitui district: a new focus of the disease. East African Medical Journal, 71, 424-428.

Myskova, J., Svobodova, M., Beverley, S. M., \& Volf, P. (2007). A lipophosphoglycan-independent development of Leishmania in permissive sand flies. Microbes and Infection, 9(3), 317-324. https://doi.org/10.1016/j.micinf.2006.12.010

Novo, S. P. C., Leles, D., Bianucci, R., \& Araujo, A. (2015).Leishmania tarentolae molecular signatures in a 300 hundred-years-old human Brazilian mummy. Parasites and Vectors, 8, 72. https://doi.org/10.1186/s13071-015-0666-z 
Noyes, H. A., Arana, B. A., Chance, M. L., \& Maingon, R. (1997). TheLeishmania hertigi (Kinetoplastida; Trypanosomatidae) complex and the lizard Leishmania : their classification and evidence for a neotropical origin of the Leishmania -endotrypanum clade. Journal of Eukaryotic Microbiology, 44(5), 511-517. https://doi.org/10.1111/j.1550-7408.1997.tb05732.x

Nzelu, C. O., Kato, H., Puplampu, N., Desewu, K., Odoom, S., Wilson, M. D., Sakurai, T., Katakura, K., \& Boakye, D. A. (2014). First Detection of Leishmania tropica DNA and Trypanosoma Species inSergentomyia sand flies (Diptera: Psychodidae) from an outbreak area of cutaneous leishmaniasis in Ghana. PLoS Neglected Tropical Diseases, 8(2), e2630. https://doi.org/10.1371/journal.pntd.0002630

Ozbel, Y., Karakuş, M., Arserim, S., Kalkan, Ş., \& Töz S. (2016). Molecular detection and identification of Leishmania spp. in naturally infected Phlebotomus tobbi and Sergentomyia denta$t a$ in a focus of human and canine leishmaniasis in western Turkey. Acta Tropica, 155, 89-94. https://doi.org/10.1016/j.actatropica.2015.12.018

Parvizi, P., \& Amirkhani, A. (2008). Mitochondrial DNA characterization of Sergentomyia sintoni populations and finding mammalianLeishmania infections in this sandfly by using ITS-rDNA gene. Iranian Journal of Veterinary Research 9, 9-18.

Pombi, M., Giacomi, A., Barlozzari, G., Mendoza-Roldan, J., Macrì, G., Otranto, D., \& Gabrielli, S. (2020). Molecular detection ofLeishmania (Sauroleishmania) tarentolae in human blood and Leishmania (Leishmania ) infantum inSergentomyia minuta : unexpected host-parasite contacts. Medical and Veterinary Entomology. https://doi.org/10.1111/mve.12464

Pozio, E., L. Gradoni, R., Bonarelli, N., Squitterin, S., Bettini, M., Maroli, M., \& Cochi, 1983: Indagini sui focolai dei flebotomi in provincial de Grosseto. Atti XII Congresso Nazionale Italiano di Entomologia, 2, 395-400.

Raymond, F., Boisvert, S., Roy, G., Ritt, J., Légaré, D., Isnard, A., Stanke, M., Olivier, M., Tremblay, M.J., Papadopoulou, B., Ouellette, M., \& Corbeil, J. (2012). Genome sequencing of the lizard parasiteLeishmania tarentolae reveals loss of genes associated to the intracellular stage of human pathogenic species. Nucleic Acids Research, 40, 1131-1147.

Schönian, G., Kuhls, K., \& Mauricio, I. L. (2010). Molecular approaches for a better understanding of the epidemiology and population genetics of Leishmania . Parasitology 138, 405-425. https://doi.org/10.1017/S0031182010001538

Senghor, M. W., Niang, A. A., Depaquit, J., Ferté, H., Faye, M. N., Elguero, E., Gaye, O., Alten, B., Perktas, U., Cassan, C., Faye, B., \& Bañuls, A. L. (2016). Transmission of Leishmania infantum in the canine leishmaniasis focus of Mont-Rolland, Senegal: ecological, parasitological and molecular evidence for a possible role ofSergentomyia sand flies. PLoS Neglected Tropical Diseases, 10(11) e0004940. https://doi.org/10.1371/journal.pntd.0004940

Simpson, L., \& Holzjr, G. (1988). The status of Leishmania tarentolae / Trypanosoma platydactyli . Parasitology Today, 4, 115-118. https://doi.org/10.1016/0169-4758(88)90043-9

Siripattanapipong, S., Leelayoova, S., Ninsaeng, U., \& Mungthin, M. (2018). Detection of DNA of Leishmania siamensis inSergentomyia (Neophlebotomus ) iyengari (Diptera: Psychodidae) and molecular identification of blood meals of. Journal of Medical Entomolology, 55, 1277-1283. https://doi.org/10.1093/jme/tjy069

Sloboda, M., Bulantová, J., Votypka, J., \& Modry, D. (2007). A new species of Hepatozoon (Apicomplexa : Adeleorina) fromPython regius (Serpentes : Pythonidae) and its experimental transmission by a mosquito vector the neurotropic Schistosome Trichobilharzia regenti in vertebrates: immune response, pathology. Journal of Parasitology, 93, 1189-1198. https://doi.org/10.1645/GE-1200R.1

Sobrino, R., Ferroglio, E., Oleaga, A., Romano, A., Millan, J., Revilla, M., Arnal, M.C., Trisciuoglio, A., \& Gortazar, C. (2008). Characterization of widespread canine leishmaniasis among wild carnivores from Spain. 
Veterinary Parasitology, 155(3-4), 198-203. https://doi.org/10.1016/j.vetpar.2008.05.003

Solano-Gallego, L., Fernandez-bellon, H., Serra, P., Gallego, M., Ramis, A., Fondevila, D., \& Ferrer, L. (2003). Cutaneous leishmaniosis in three horses in Spain. Equine Veterinary Journal, 35(3), 320-323. https://doi.org/10.2746/042516403776148336

Tarallo, V. D., Dantas-Torres, F., Lia, R. P., \& Otranto, D. (2010). Phlebotomine sand fly population dynamics in a leishmaniasis endemic peri-urban area in southern Italy. Acta Tropica, 116(3), 227-234. https://doi.org/10.1016/j.actatropica.2010.08.013

Tateng, A. N., Kirstein, O. D., Ngouateu, O. B., Kruger, A., von Stebut, E., Maurer, M., Payne, V.K., Warburg, A., \& Dondji, B. (2018). First detection of Leishmania donovani in sand flies from Cameroon and its epidemiological implications. Tropical Medicine and International Health, 23(9), 10141021. https://doi.org/10.1111/tmi.13123

Taylor, V. M., Munoz, D. L., Cedeno, D. L., Velez, I. D., Jones, M. A., \& Robledo, S. M. (2010). Leishmania tarentolae : utility as an in vitro model for screening of antileishmanial agents. Experimental Parasitology, 126(4), 471-475. https://doi.org/10.1016/j.exppara.2010.05.016

Telford, S. R. (1995, May). A review of trypanosomes of gekkonid lizards, including the description of five new species. Systematic Parasitology, Vol. 31, pp. 37-52. https://doi.org/10.1007/BF00009301

Tuon, F. F., Amato Neto, V., \& Sabbaga Amato, V. (2008).Leishmania : origin, evolution and future since the Precambrian. FEMS Immunology \& Medical Microbiology, 54(2), 158-166. https://doi.org/10.1111/j.1574-695X.2008.00455.x

Ursula, H., Rudiger, K., Frank, M., \& Monika, R. (2014). Blood parasites in reptiles imported to Germany. Parasitology Research, 113(12), 4587-4599. https://doi.org/10.1007/s00436-014-4149-5

Van Der Auwera, G., \& Dujardin, J.C. (2015). Species Typing in dermal leishmaniasis. Clincal Microbiology Reviews, 28, 265-294. http://doi.org/10.1128/CMR.00104-14.

Vaselek, S., Ayhan, N., Oguz, G., Erisoz Kasap, O., Savić, S., Di Muccio, T., Gradoni, L., Ozbel, Y., Alten, B., \& Petrić, D. (2017). Sand fly and Leishmania spp. survey in Vojvodina (Serbia): first detection of Leishmania infantum DNA in sand flies and the first record of Phlebotomus (Transphlebotomus ) mascittiiGrassi, 1908. Parasites and Vectors, 10(1), 44. https://doi.org/10.1186/s13071-017-2386-z

Wang, M. Z., Zhu, X., Srivastava, A., Liu, Q., Sweat, J. M., Pandharkar, T., Stephens, C.E., Riccio, E., Parman, T., Munde, M., Mandal, S., Madhubala, R., Tidwell, R.R., Wilson, W.D., Boykin, D.W., Hall, J.E., Kyle, D.E., \& Werbovetz, K. A. (2010). Novel arylimidamides for treatment of visceral leishmaniasis. Antimicrobial Agents and Chemotherapy, 54(6), 2507-2516. https://doi.org/10.1128/AAC.00250-10

Wilson, V., Southgate, B. (1979). Lizard Leishmania. In: Lumsden W., Evans D. (eds.). Biology of Kinetoplastida. New York: Academic.

Zhang, J. R., Guo, X. G., Chen, H., Liu, J. L., Gong, X., Chen, D. L., \& Chen, J. P. (2019). Pathogenic Leishmania spp. detected in lizards from Northwest China using molecular methods. BMC Veterinary Research, 15(1), 1-13. https://doi.org/10.1186/s12917-019-2174-4

Zhang, J. R., Guo, X. G., Liu, J. L., Zhou, T. H., Gong, X., Chen, D. L., \& Chen, J. P. (2016). Molecular detection, identification and phylogenetic inference of Leishmania spp. in some desert lizards from Northwest China by using internal transcribed spacer 1 (ITS1) sequences. Acta Tropica, 162, 83-94. https://doi.org/10.1016/j.actatropica.2016.06.023

\section{TABLE 1}

Samples of phlebotomine sand flies used to assess the analytical specificity of the duplex quantitative PCR. The mean threshold cycle (Cq), parasite load (Starting Quantity (SQ), value expressed as ng/ $\mu$ of DNA for 
reaction) and the mean, minimum, maximum and standard deviation (SD) of values of the threshold cycle $(\mathrm{Cq})$ are reported forLeishmania infantum and Leishmania tarentolae assessed by assay is reported

\begin{tabular}{|c|c|c|c|c|c|c|c|c|c|c|c|c|c|c|}
\hline \multirow{3}{*}{\multicolumn{2}{|c|}{ 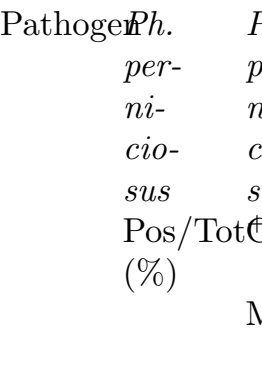 }} & $\begin{array}{l}\text { Ph. } \\
\text { per- } \\
\text { ni- } \\
\text { cio- } \\
\text { sus }\end{array}$ & $\begin{array}{l}\text { Ph. } \\
\text { per- } \\
\text { ni- } \\
\text { cio- } \\
\text { sus }\end{array}$ & $\begin{array}{l}\text { Ph. } \\
\text { per- } \\
\text { ni- } \\
\text { cio- } \\
\text { sus }\end{array}$ & $\begin{array}{l}\text { Ph. } \\
\text { per- } \\
\text { ni- } \\
\text { cio- } \\
\text { sus }\end{array}$ & $\begin{array}{l}\text { Ph. } \\
\text { per- } \\
\text { ni- } \\
\text { cio- } \\
\text { sus }\end{array}$ & $\begin{array}{l}\text { Ph. } \\
\text { per- } \\
\text { ni- } \\
\text { cio- } \\
\text { sus }\end{array}$ & $\begin{array}{l}\text { Se. } \\
\text { min- } \\
u t a^{+}\end{array}$ & $\begin{array}{l}\text { Se. } \\
\text { min- } \\
u t a^{+}\end{array}$ & $\begin{array}{l}\text { Se. } \\
\text { min- } \\
u t a^{+}\end{array}$ & $\begin{array}{l}\text { Se. } \\
\text { min- } \\
\text { uta }\end{array}$ & $\begin{array}{l}\text { Se. } \\
\text { min- } \\
u t a^{+}\end{array}$ & $\begin{array}{l}\text { Se. } \\
\text { min- } \\
u t a^{+}\end{array}$ & $\begin{array}{l}\text { Se. } \\
\text { min- } \\
u t a^{+}\end{array}$ \\
\hline & & $t \notin \frac{1}{q}$ & $\mathrm{Cq}$ & $\mathrm{Cq}$ & $\mathrm{SQ}$ & SQ & SQ & \multicolumn{2}{|c|}{$\begin{array}{l}\text { Pos/TotCq } \\
(\%)\end{array}$} & $\mathrm{Cq}$ & $\mathrm{Cq}$ & SQ & SQ & $\mathrm{SQ}$ \\
\hline & & Mean & $\begin{array}{l}\text { Min- } \\
\max ^{++}\end{array}$ & SD & Mean & $\begin{array}{l}\text { Min- } \\
\max \end{array}$ & $\mathrm{SD}$ & & Mean & $\begin{array}{l}\text { Min- } \\
\max \end{array}$ & SD & Mean & $\begin{array}{l}\text { Min- } \\
\max \end{array}$ & $\mathrm{SD}$ \\
\hline $\begin{array}{l}L . \\
\text { in- } \\
\text { fan- } \\
\text { tum }\end{array}$ & $\begin{array}{l}5 / 140 \\
(3.6)\end{array}$ & 33.3 & $\begin{array}{l}20.5- \\
37.5\end{array}$ & 7.2 & 3 & $\begin{array}{l}2.1 \times 10^{-6} \\
3.3 \times 10\end{array}$ & & $\begin{array}{l}6 / 171 \\
(3.5)\end{array}$ & 35.2 & $\begin{array}{l}33.3- \\
37.6\end{array}$ & 1.6 & $2.2 \times 10^{-5}$ & $\begin{array}{l}5.5 \times 10^{-6} \\
5.6 \times 10^{-5}\end{array}$ & ${ }^{6} 1.8 \times 10^{-5} 0$ \\
\hline $\begin{array}{l}\text { L. } \\
\text { tar- } \\
\text { en- }\end{array}$ & $\begin{array}{l}2 / 140 \\
(1.4)\end{array}$ & 35.9 & $\begin{array}{l}35.7- \\
36.1\end{array}$ & 0.3 & $2.1 \times 10^{-6}$ & $\begin{array}{l}1.8 \\
\times 10^{-6}\end{array}$ & $\begin{array}{l}4.9 \\
\times 10^{-7}\end{array}$ & $\begin{array}{l}50 / 171 \\
(29.2)\end{array}$ & 33.0 & $\begin{array}{l}18.5- \\
38.9\end{array}$ & 5.9 & 4.09 & $\begin{array}{l}8.8 \times 10^{-7} \\
7.9 \times 10^{1}\end{array}$ & $1.52 \times 10^{1} 0$ \\
\hline $\begin{array}{l}\text { to- } \\
\text { lae }\end{array}$ & & & & & & $2.5 \times 10^{-6}$ & & & & & & & & \\
\hline $\begin{array}{l}\text { Total } \\
\text { (Pos/T } \\
\%)\end{array}$ & $\begin{array}{l}7 / 140 \\
(5)\end{array}$ & - & - & - & - & - & - & $\begin{array}{l}56^{*} / 171 \\
(32.7)\end{array}$ & & - & - & - & - & - \\
\hline
\end{tabular}

+ Se. minuta $(n=2)$ scored positive for both L. infantum and L. tarentolae

++ Pos, positive; Tot, total; Min, minimum; Max, maximum

\section{TABLE 2}

DNA from lizard tissues samples spiked with DNA of Leishmania infantum and/or Leishmania tarentolae tested by duplex quantitative PCR. The mean, minimum, maximum and standard deviation (SD) of values of the threshold cycle $(\mathrm{Cq})$ are reported

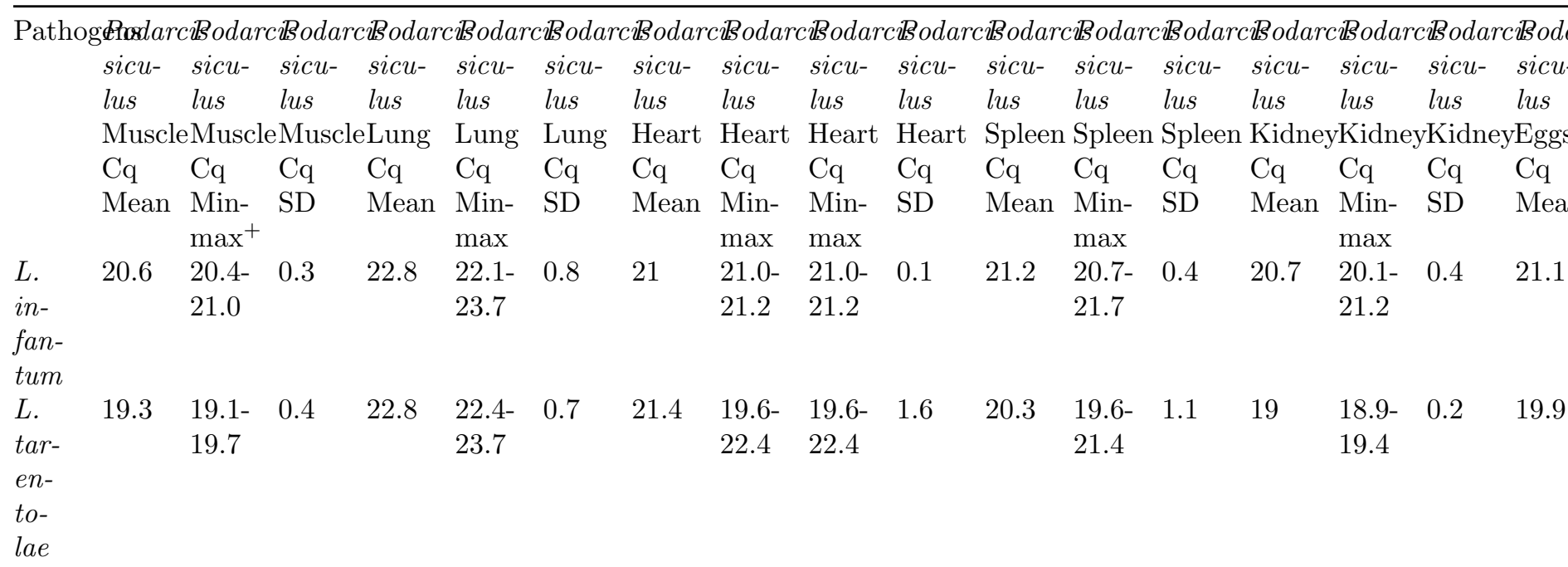




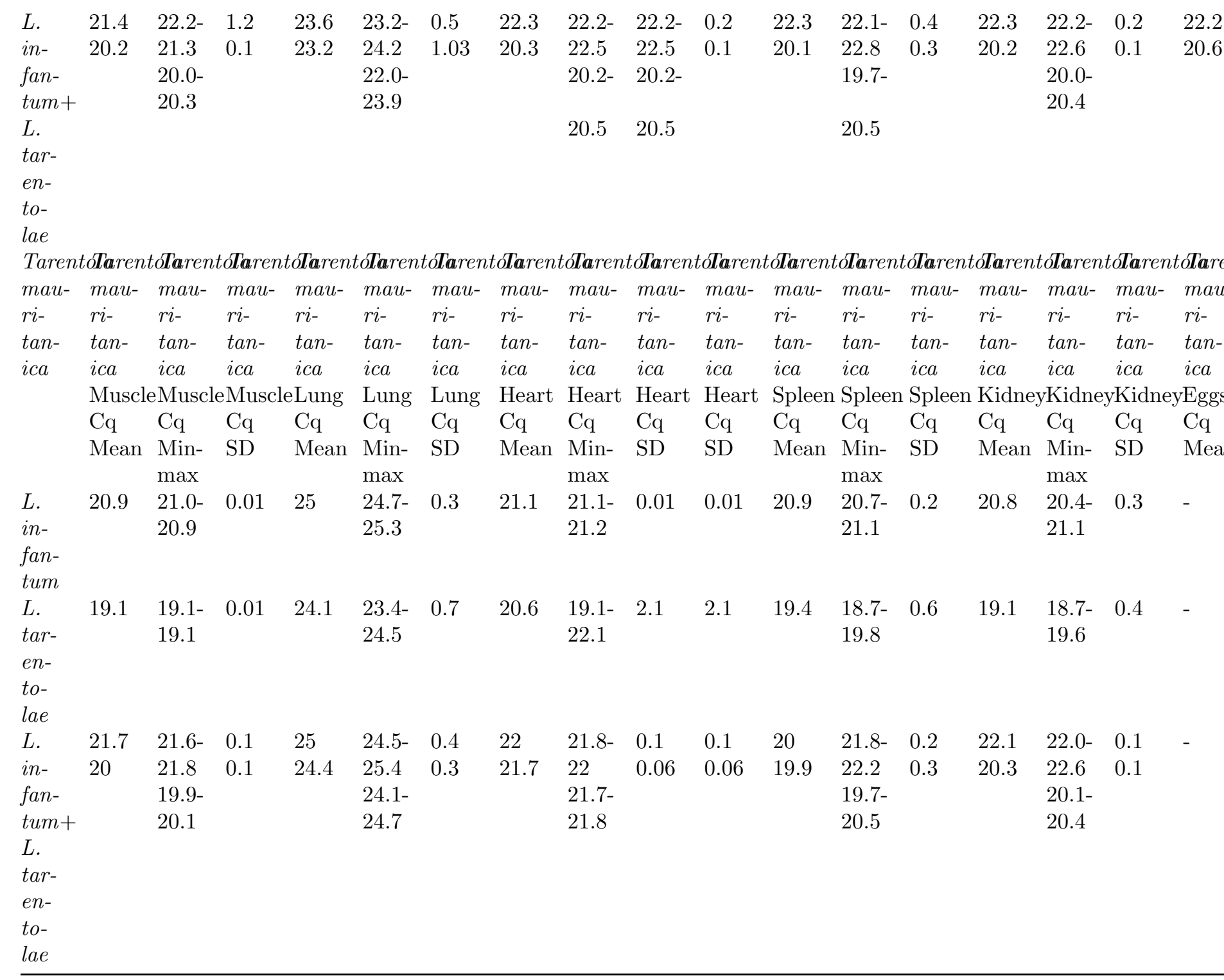

+ Pos, positive; Tot, total; Min, minimum; Max, maximum

Figure legends

FIGURE 1 Assessment of the specificity of dqPCR assay in the detection of Leishmania spp. DNA. The amplification plot represented by the fluorescent signal, accordingly to relative fluorescence units (RFU) and threshold cycle and standard curves generated from serial dilutions of genomic DNA from L. tarentolae(A), L. infantum (B) and for spiked DNA of L. infantum and L. tarentolae (C) 

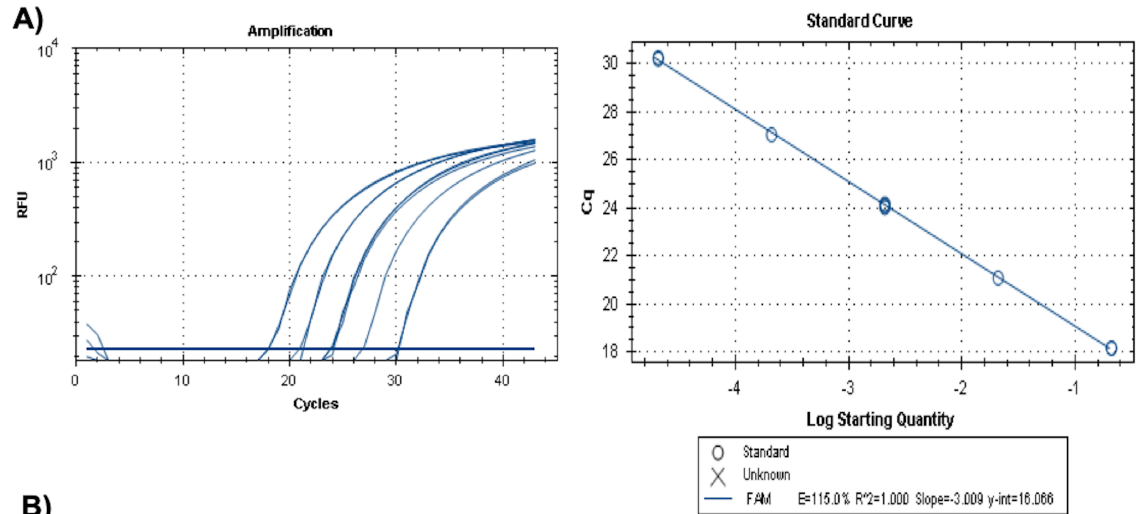

B)

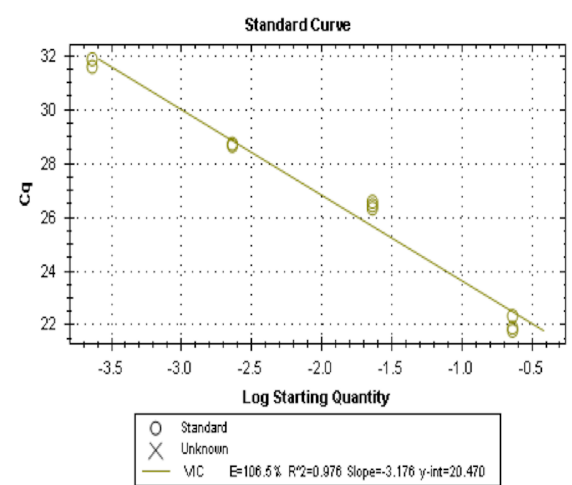

C)
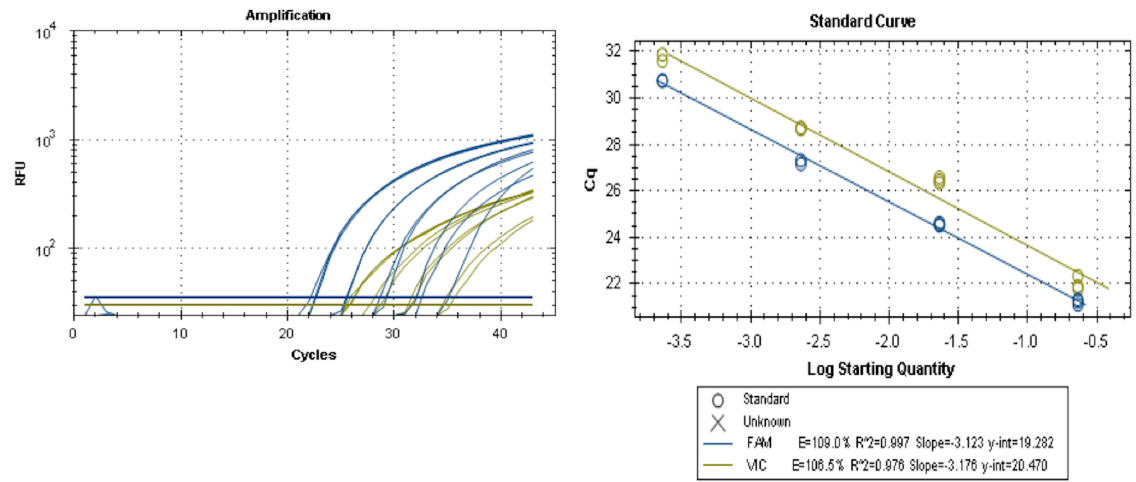